NBER WORKING PAPER SERIES

\title{
VEHICLE CHOICES, MILES DRIVEN AND POLLUTION POLICIES
}

\author{
Ye Feng \\ Don Fullerton \\ Li Gan \\ Working Paper 11553 \\ http://www.nber.org/papers/w11553 \\ NATIONAL BUREAU OF ECONOMIC RESEARCH \\ 1050 Massachusetts Avenue \\ Cambridge, MA 02138 \\ August 2005
}

We are grateful for financial support from Japan's Economic and Social Research Institute (ESRI), and for suggestions from Chunrong Ai, Frank Convery, Stephen Donald, Hilary Sigman, Dan Slesnick, Ken Train, Sarah West, and Cliff Winston. This paperi s part of the NBER's research program in Public Economics. Any opinions expressed are those of the authors and not those of the ESRI or the National Bureau of Economic Research. The views expressed herein are those of the author(s) and do not necessarily reflect the views of the National Bureau of Economic Research.

(C)2005 by Ye Feng, Don Fullerton and Li Gan. All rights reserved. Short sections of text, not to exceed two paragraphs, may be quoted without explicit permission provided that full credit, including (C) notice, is given to the source. 
Vehicle Choices, Miles Driven, and Pollution Policies

Ye Feng, Don Fullerton and Li Gan

NBER Working Paper No. 11553

August 2005

JEL No. D12, H23, Q58

\section{$\underline{\text { ABSTRACT }}$}

Mobile sources contribute large percentages of each pollutant, but technology is not yet available to measure and tax emissions from each vehicle. We build a behavioral model of household choices about vehicles and miles traveled. The ideal-but-unavailable emissions tax would encourage drivers to abate emissions through many behaviors, some of which involve market transactions that

can be observed for feasible market incentives (such as a gas tax, subsidy to new cars, or tax by vehicle type). Our model can calculate behavioral effects of each such price and thus calculate car choices, miles, and emissions.

A nested logit structure is used to model discrete choices among different vehicle bundles. We also consider continuous choices of miles driven and the age of each vehicle. We propose a consistent estimation method for both discrete and continuous demands in one step, to capture the interactive effects of simultaneous decisions. Results are compared with those of the traditional sequential estimation procedure.

Ye Feng

Department of Economics University of Texas Austin, TX 78712-1173

yfeng@eco.utexas.edu

Don Fullerton

Department of Economics

University of Texas

Austin, TX 78712-1173

dfullert@eco.utexas.edu

\section{Li Gan}

Department of Economics

University of Texas

Austin, TX 78712

gan@eco.utexas.edu 
The standard case for market-based incentives requires a tax or price on each unit of emissions. Each form of abatement is then pursued until the marginal cost of reducing pollution matches the tax per unit of pollution, and the resulting combination of abatement technologies minimizes social costs (Pigou, 1920). For vehicles, a tax on emissions could induce drivers to: (1) buy a newer, cleaner car, (2) buy a smaller, more fuel efficient car, (3) fix their broken pollution control equipment, (4) buy cleaner gasoline, (5) drive less, (6) drive less aggressively, and (7) avoid cold start-ups. ${ }^{1}$ Moreover, economic efficiency requires different combinations of these methods for different consumers: some lose little by switching to a smaller car, some could easily walk, and some just pay the tax.

Yet the technology is not available to measure each car's emissions in a reliable and cost-effective manner. On-board diagnostic equipment is imperfect, and it is costly to retrofit millions of vehicles (Harrington and McConnell, 2003). Remote sensing is less expensive and has been used to identify high-polluting vehicles, but it cannot measure emissions clearly enough to tax each car. ${ }^{2}$ Moreover, vehicle emissions are important. In 2001, vehicles in the U.S. contributed 27 percent of volatile organic compounds (VOC), 37 percent of nitrogen oxides $\left(\mathrm{NO}_{\mathrm{x}}\right)$, and 66 percent of carbon monoxide $(\mathrm{CO})$ emissions. ${ }^{3}$

For these reasons, vehicle emission policies have relied almost solely on mandates: refineries must make clean gasoline, and new cars must meet required emission standards. ${ }^{4}$ These command and control (CAC) policies miss the opportunity to reduce social costs by harnessing individual incentives, however, as the mandated combination of abatement methods is unlikely to match the combination that households would choose if faced with a tax on emissions. In fact, the cost of abatement using such mandates can be several times the minimum cost achieved by using an emissions tax (Newell and Stavins, 2003).

While the inability to measure emissions may preclude a vehicle emissions tax, it does not preclude any use of incentives. Those who sell new or used cars or light-trucks

\footnotetext{
${ }^{1}$ Heeb et al (2003) find that cold start emissions rates (in $\mathrm{g} / \mathrm{km}$ traveled) exceed stabilized emissions rates by a factor of two to five, depending on the pollutant. Sierra Research (1994) finds that a car driven aggressively has carbon monoxide emissions that are almost 20 times higher than when driven normally.

${ }^{2}$ See Sierra Research (1994). Remote sensing in Texas (http://www.tnrcc.state.tx.us/air/ms/vim.html\#im3) and Albuquerque NM (http://www.cabq.gov/aircare/rst.html) is used in 2005 to identify polluting vehicles.

${ }^{3}$ See http://www.bts.gov/publications/transportation_statistics_annual_report/2004/. We focus on local pollutants, where emission rates depend on car characteristics. In contrast, $\mathrm{CO}_{2}$ is linked directly to gas use.

${ }^{4}$ In the U.S., new cars face emission standards of $.254 \mathrm{grams} / \mathrm{km}$ of HC's, $2.11 \mathrm{grams} / \mathrm{km}$ of CO, and .248 grams $/ \mathrm{km}$ of $\mathrm{NO}_{\mathrm{x}}$. Light trucks face a variety of weaker standards, but all are scheduled to become more stringent. These figures pertain to a test in the U.S. with a cold start-up phase, a transient phase at different speeds, and a hot start phase, for a total distance of $18 \mathrm{~km}$ at an average speed of $34 \mathrm{~km} / \mathrm{h}$.
} 
can collect tax on vehicle characteristics that are associated with emissions, or provide subsidy for vehicles with low emissions. Most states charge annual registration fees that can be made to depend on vehicle characteristics. Such policies might reduce emission rates, while changes in the gasoline tax can reduce miles driven. ${ }^{5}$

What vehicle characteristics or behaviors should be targeted by a tax or subsidy? How would consumers react to those new incentive instruments? How much would each tax reduce emissions? To address these questions, we build a general purpose model of discrete choices by households about how many cars to own and what types of cars to own, plus continuous choices about how far to drive. In our model, we embrace individual heterogeneity. We estimate all decisions simultaneously, and we use the estimated parameters to predict the effects of certain price changes on choices and on emissions.

Several existing papers explore market incentives that could be used in place of a tax on emissions. ${ }^{6}$ In addition, several papers estimate models of the discrete choice among vehicle bundles (including number, size, and age categories). ${ }^{7}$ Some models estimate the demand for gasoline or for vehicle miles traveled (VMT) as functions of price and income (as reviewed in Harrington and McConnell, 2003). As well, we note that other models predict emissions. ${ }^{8}$ A major contribution of our research, then, is to include all such choices simultaneously. In general, we capture the effect of any price change on each household's choices about the number of vehicles to buy, the type and age of each, the consequent emissions rates, miles driven, and the consequent total emissions.

In a two-step procedure, Dubin and McFadden (1984) estimate a discrete choice model (for household appliances) and use the predicted shares to correct for endogeneity in the estimation of a continuous choice (usage hours). Others extend this model to the discrete choice among vehicle bundles and a continuous choice of miles (e.g. Goldberg, 1998, and West, 2004). Yet, a single set of parameters appear both in the indirect utility

\footnotetext{
${ }^{5}$ A new higher gas tax may be politically unlikely, yet it is still worth studying to know its power as an emissions-reduction tool. And even if governments are unlikely to use tax dollars to pay for the various subsidies we study here, these incentives might instead be provided to drivers by private companies that want to purchase "offsets" - reductions in vehicle emissions to offset their increases from stationary sources. For all of these reasons, we find it important to study specific incentives to drivers.

${ }^{6}$ For examples, see Eskeland and Devarajan (1996), Innes (1996), Kohn (1996), Train et al (1997), Plaut (1998), Sevigny (1998), and Fullerton and West (2000, 2002).

${ }^{7}$ See McFadden (1979), Mannering and Winston (1985), Train (1986), Brownstone et al (1996), Goldberg (1998), Brownstone and Train (1999), West (2004), and other papers reviewed in McFadden (2001).

${ }^{8}$ For example, the U.S. Environmental Protection Agency (U.S. EPA, 1998, p.3-68) discusses the use of EPA's MOBILE5a model or California's EMFAC7F model.
} 
function used to estimate discrete choices and in continuous demands. Using this sequential procedure, the estimated parameters of the continuous demand are not constrained to match the same parameters in the estimated discrete choice model.

Relative to this literature, we make a number of contributions. First, we capture the simultaneity of these decisions by proposing a method for consistent estimation of both discrete and continuous choices in one step, yielding a single set of parameters. In other words, whereas the Dubin-McFadden method corrects for selection of vehicle on the choice of miles, our simultaneous procedure also allows for heterogeneity in actual fuel demand to affect the choice of vehicle. ${ }^{9}$ Second, we allow for two continuous choices of miles - in each vehicle of a two-vehicle household. These choices are bundle-specific. ${ }^{10}$ Third, we allow for an additional continuous choice of the age of each vehicle. Fourth, we use the estimated parameters not only to predict changes in choices about vehicles and miles, but also how those choices affect emissions. ${ }^{11}$

For several reasons, we deviate from discrete vehicle types used in prior literature (including age and size categories). First, we have no need to model the choice among hundreds of vehicle types, as in prior studies of manufacturer product differentiation, since all cars in a given year are made to a single emission rate standard. Second, a different, weaker emission standard has applied to "sports utility vehicles" (SUV, for short, but defined here to include all light trucks and vans). Emission rules for new vehicles do not depend on engine size. We therefore model the choice between car and SUV, rather than engine size. Even for older vehicles, when we use data described below in separate regressions for cars and SUV's, we find that engine size is not an important determinant of emission rates. Third, those regressions find that vehicle age is very important for emission rates. We wish not to lose information by aggregation into finite age categories (e.g. new

\footnotetext{
${ }^{9}$ Hanemann (1984) proposes a method to estimate these demands simultaneously, but his method does not consider unobserved individual heterogeneity - a key factor in the Dubin-McFadden model. Our model captures the individual unobserved heterogeneity. Bento et al (2005) and Bhat (2005) are also working on models with simultaneous discrete and continuous choices.

${ }^{10}$ With a higher price of gas, some households might drive fewer miles in their SUV and more in their car. We do not estimate separately the miles in each vehicle, but we do estimate a change for the (Car, SUV) bundle that can differ from the (Car, Car) bundle. Other papers have estimated substitution between vehicles within the family, but they treat the vehicles as given rather than chosen. Greene and $\mathrm{Hu}$ (1985) find that this kind of substitution occurs to a large extent in some households, while Sevigny (1998) finds small effects.

${ }^{11}$ Our household responses represent market outcomes only if supply curves were horizontal. The simulation of a change in the price of getting a car that is one year newer can be interpreted as a new local tax or subsidy in a small open jurisdiction that can import more of those newer cars at a constant price. However, our demand system could be combined with some other estimates of supply to calculate equilibrium outcomes.
} 
vs. old). Age is a continuous variable, and the choice of vehicle age is a continuous demand that affects emissions. ${ }^{12}$ If a household in our model chooses to own two vehicles, then it has four continuous choices: age of each vehicle and miles to drive each vehicle. ${ }^{13}$

Age is normally measured in years, of course, but our model requires a price that does not depend on the amount demanded. The price of age is not linear, because owning a brand-new car costs more depreciation per year than owning an old car. Instead of using age in years, we therefore construct a continuous choice variable called "Wear" that measures the fraction of the vehicle that has depreciated (between 0 and 1). A constant rate of depreciation means that Wear is a nonlinear function of age, but then the price per unit of Wear does not depend on its amount. This constant price is estimated for each vehicle type using hedonic price regressions below. Next, in order to separate this choice of vehicle attribute from the choice of vehicle, we assume that the discrete choice is about a brand-new "concept vehicle." Then the household gets reimbursed by the price of Wear for accepting an older car. In other words, in our model, a household makes simultaneous decisions about which concept vehicles, how old, and miles to drive.

As it turns out, results for all continuous demands are broadly similar for the sequential and simultaneous models. For discrete choices, however, our simultaneous model finds substantially larger effects from a change in the gas price per mile, income, or vehicle-specific costs. Signs of some elasticities are reversed. In other words, householdspecific heterogeneity does affect discrete choices.

The next section describes a behavioral choice model for one-vehicle households and then extends it to consider two-vehicle bundles. It also presents a new method designed for jointly estimating all discrete and continuous choices. Section II describes data sources and provides summary statistics, while III provides estimation results for both discrete and continuous demands. Section IV compares elasticities, and V concludes.

\section{The Model and Estimation}

In our model, an agent representing each household faces a discrete choice among a finite number of vehicle bundles. The nesting structure is shown in Figure 1. One

\footnotetext{
${ }^{12}$ Older vehicles have higher emissions both because older vintages were produced to weaker standards and because pollution control equipment deteriorates with age. Panel data would be required to distinguish these.

${ }^{13}$ Fullerton and West (2000) also simulate effects of incentives in a model of heterogeneous households' continuous choices of car size, car age, and VMT, but they use calibrated rather than estimated parameters. That model avoids discrete choices, but it considers only one car per agent. In our model, we estimate discrete choices to consider the household's number of vehicles.
} 
choice is the number of vehicles $(0,1$, or 2$)$, and another choice for each vehicle is the type of vehicle (a car or an SUV). We thus have six final bundles, as shown in the figure and listed in Table 1. Other choices important for emissions of each vehicle are the continuous choice about vehicle miles traveled $(V M T)$ and vehicle age. To obtain a choice variable with a linear price, we construct "Wear" as the fraction of the vehicle used up by depreciation. It is calculated for each car in our sample by assuming $20 \%$ depreciation per year, so Wear $=1-(1-0.2)^{\text {age }}$. Thus, a new car has Wear $=0$.

Figure 1: Nesting Structure for Choice among Vehicle Bundles

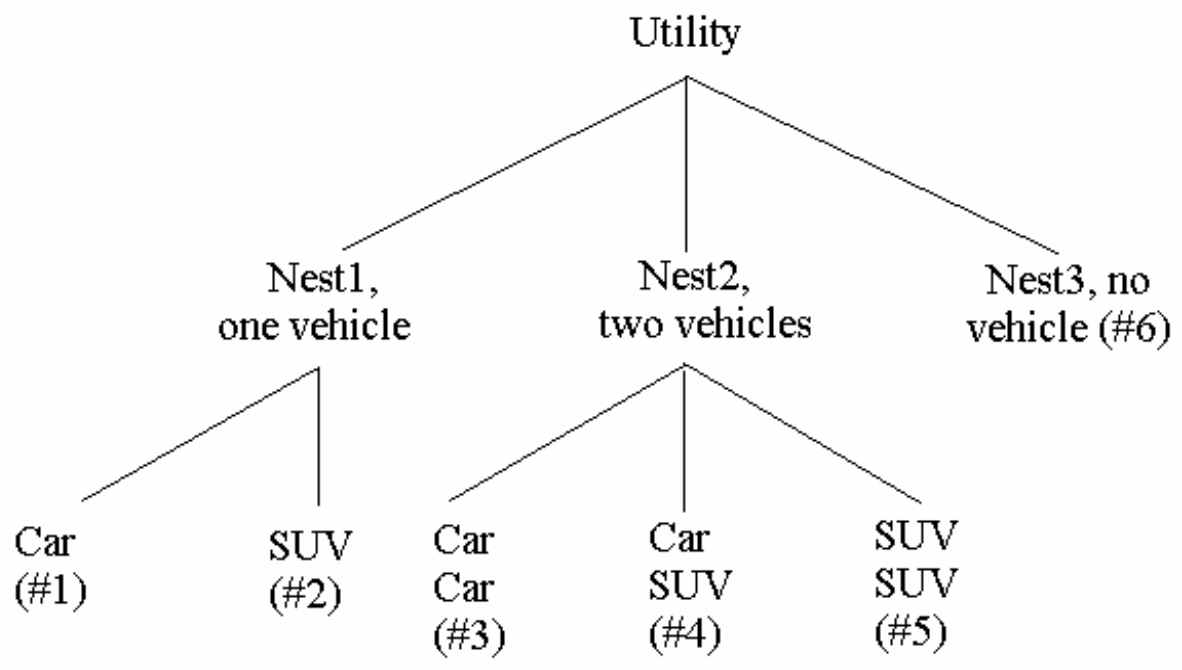

Then, since choice of age is considered separately, each discrete vehicle bundle must be defined in a way that is independent of age. For this reason, we define each "concept" vehicle as a bundle of attributes of a brand-new vehicle (car or SUV). The household must pay the price of that brand-new vehicle (the "capital cost"), but then it gets back some money for accepting Wear on that vehicle (the "reimbursement" price of Wear).

Our demand system now has several distinguishing characteristics. First, it incorporates all of these discrete and continuous choices simultaneously. Second, some unobserved characteristics might affect both kinds of choices. For example, an agent who lives far from work may drive more and thus prefer a larger, more comfortable car. Yet, a more comfortable car may increase the satisfaction of driving and thus induce the driver to drive more. Third, many households have two cars with multiple continuous choices. Consequently, the substitution structure in VMT and Wear among different vehicles is important in order to understand the effects of policy on driving behavior. 
Since the discrete choice in Dubin and McFadden (1984) involves only two alternatives, that paper can use a simple logit model. Our model has six choices, however, and so we require a more general logit structure. We use the nested logit. The next sub-section describes the simple case for households with only one vehicle, and the second subsection considers multi-vehicle households. In the third and fourth subsections, we discuss the estimation procedure and elasticity calculations.

\section{A. Our Model of Car Choice and Miles Driven}

This description starts with the choices of VMT and Wear, assuming that a onecar household has already chosen vehicle number-and-type bundle $i$. Given bundle $i$, an agent's direct utility is a function of VMT, Wear, and another consumption good $c$. That is, $U=U\left(V M T_{i}\right.$, Wear $\left._{i}, c_{i}\right)$. Given income $y$, the budget constraint is given by:

$$
\frac{p_{g}}{M P G_{i}} V M T_{i}-q_{i} \text { Wear }_{i}+c_{i}=y-r_{i}
$$

where $p_{g}$ is the price of gasoline (in dollars per gallon), and $M P G_{i}$ is fuel efficiency (in miles per gallon), so that $p_{i} \equiv p_{g} / M P G_{i}$ is the marginal price per mile in the $i^{\text {th }}$ vehicle bundle. The "reimbursement" price of Wear for vehicle type $i$ is denoted as $q_{i}$. The price of the other consumption good is normalized to be 1 . The annualized capital cost of the concept-vehicle bundle is $r_{i}$. Thus, gasoline is the only cost per mile, whereas capital cost is a fixed cost of each bundle. ${ }^{14}$ The indirect utility for bundle $i$ is a function of household income and prices, denoted as $V\left(y-r_{i}, p_{i}, q_{i}\right)$.

One common way to obtain the indirect utility function is to use parametric demand and then solve a system of partial differential equations using Roy's identity (Hausman, 1981). For comparability with other studies, we want VMT demand as a log-linear function of the price per mile $p_{i}$, available income $y-r_{i}$, and a vector of observed sociodemographic variables $x$. We then add the reimbursement price $q_{i}$ to that equation to get:

$$
\ln \left(V M T_{i}\right)=\alpha_{V}^{i}+\alpha_{p}^{i} p_{i}-\alpha_{q} q_{i}-\beta\left(y-r_{i}\right)+x^{\prime} \gamma+\eta
$$

where $\eta$ represents an agent-specific unobserved factor (see below). Also, we assume

$$
r_{i}=(\delta+\rho) k_{i}
$$

\footnotetext{
${ }^{14}$ Time variation in gasoline prices may cause time variation in used vehicle prices. Our use of cross-section data helps avoid this problem.
} 
where $k_{i}$ is the total capital value of bundle $i$ (depreciated or market value), $\delta$ is the annual rate of further depreciation in value, and $\rho$ represents the interest and maintenance cost. When we plug (3) into (2) and integrate, the implied indirect utility is:

$$
V_{i}=\frac{1}{\beta} \exp \left(-\alpha_{0}^{i}+\beta y-\beta_{1} k_{i}-x^{\prime} \gamma-\eta\right)-\frac{1}{\alpha_{p}^{i}} \exp \left(\alpha_{p}^{i} p_{i}-\alpha_{q} q_{i}\right)+\varepsilon_{i},
$$

where $\beta_{1}=\beta(\delta+\rho){ }^{15}$ This equation includes an extra additive error $\varepsilon_{i}$ that is bundlespecific. As in the usual discrete choice model, this error term represents the difference between true individual utility at choice $i$ and the calculated utility level. ${ }^{16}$ For households who choose the no-vehicle bundle \#6, continuous variables such as $p_{i}, q_{i}$, and $V M T_{i}$ are unobservable. Implicitly, we assume that these households may purchase a bicycle or a fare card for public transportation with a fixed fee, similar to the capital cost $k_{i}$. With no cost per mile or of Wear, their second exponential term in (4) is 1.0. Their capital cost $k_{i}$ is unobserved, so $\beta_{1} k_{i}$ and $\alpha_{0}^{6}$ are not separately identifiable. Since we allow for a choice-specific intercept, however, we combine both terms into one constant, $\alpha_{0}^{6}$.

Note that the simple addition of $\alpha_{q} q_{i}$ to equation (2) dictates the form of indirect utility in (4). This indirect utility then implies specific forms for both demands: ${ }^{17}$

$$
\begin{aligned}
& \ln \left(V M T_{i}\right)=\alpha_{V}^{i}+\alpha_{p}^{i} p_{i}-\alpha_{q} q_{i}-\beta y+\beta_{1} k_{i}+x^{\prime} \gamma+\eta \\
& \ln \left(\text { Wear }_{i}\right)=\alpha_{W}^{i}+\ln \left(\alpha_{q} / \alpha_{p}^{i}\right)+\alpha_{p}^{i} p_{i}-\alpha_{q} q_{i}-\beta y+\beta_{1} k_{i}+x^{\prime} \gamma+\eta
\end{aligned}
$$

This specification has pros and cons. One limitation is the use of specific functional forms, but these log-linear forms are comparable to prior literature and allow for two different demand functions $(5 \mathrm{a}, \mathrm{b})$ that are consistent with a single indirect utility function (4). An advantage of this specification is that it allows the price of Wear $\left(q_{i}\right)$ to enter the VMT demand, and price of VMT $\left(p_{i}\right)$ to enter the Wear demand, but a

\footnotetext{
${ }^{15}$ Our model provides estimates of $\beta$ and $\beta_{l}$, and these can be used to calculate $(\delta+\rho)$, but we do not provide separate estimates of $\delta$ and $\rho$. Some of our steps below require an assumption about $\delta$, and we use 20 percent for this purpose. Estimates of the depreciation rate for automobiles range from 33\% (Jorgenson, 1996) or 30\% (Hulten and Wykoff, 1996) to 15\%, the rate implicit in the vehicle depreciation schedule currently used by the Bureau of Economic Analysis. We use $20 \%$ because it falls between these bounds.

${ }^{16}$ Also, because of this integration, note that the intercept in (4) may be different from the intercept in (2).

${ }^{17}$ More general demand functions such as translog demand or the almost ideal demand system imply much more complicated indirect utility functions that could not be estimated. Also, note that no-vehicle households have zero marginal prices, so they have constant miles traveled (conditioned on observed socio-demographic variables and total income). Thus, no continuous demand equations are needed for these households.
} 
limitation is that the expression $\alpha_{p}^{i} p_{i}-\alpha_{q} q_{i}$ enters both demands the same way. ${ }^{18}$ Also, both continuous demands have the same income effect, $\beta$. A more general model could not be estimated. Note, however, that we have added generality where it matters most. In particular, the price per mile has a bundle-specific coefficient $\left(\alpha_{p}^{i}\right)$, to allow for different effects on the demand for miles in each type of vehicle. Thus a gas tax might decrease miles in an SUV more than in a car, in a way that depends on fuel efficiency, and the change in miles of a two-car household can differ from the change in miles of a household with two SUV's (or one car and one SUV).

\section{B. Two-Vehicle Households}

So far, the model above considers only one vehicle, but many households have two vehicles and thus two continuous choices of miles and two continuous choices of Wear. We have the observed VMT and Wear for each vehicle, so we can incorporate all four continuous choices. ${ }^{19}$ The direct utility for a two-vehicle household choosing bundle $i$ is $U\left(V M T_{i 1}, V M T_{i 2}\right.$, Wear $i 1$, Wear $\left._{i 2}, c_{i}\right)$. The budget constraint is given by:

$$
\frac{p_{g}}{M P G_{i 1}} V M T_{i 1}+\frac{p_{g}}{M P G_{i 2}} V M T_{i 2}-q_{i 1}\left(\text { Wear }_{i 1}\right)-q_{i 2}\left(\text { Wear }_{i 2}\right)+c_{i}=y-r_{i}
$$

where $q_{i j}$ are reimbursement prices for Wear in the two vehicles of bundle $i(j=1,2)$. Also, $p_{i j} \equiv p_{g} / M P G_{i j}$ is the price per mile using the $j^{\text {th }}$ car of bundle $i$. We consider the indirect utility function as follows:

$$
V_{i}=\frac{1}{\beta} \exp \left(-\alpha_{0}^{i}+\beta y-\beta_{1} k_{i}-x^{\prime} \gamma-\eta\right)-\frac{1}{\alpha_{p 1}^{i}} \exp \left(\alpha_{p 1}^{i} p_{i 1}+\alpha_{p 2}^{i} p_{i 2}-\alpha_{q 1} q_{i 1}-\alpha_{q 2} q_{i 2}\right)+\varepsilon_{i}
$$

The indirect utility in (7) is similar to (4) except for two extra terms related to the second vehicle's gasoline price $p_{i 2}$ and reimbursement price $q_{i 2}$. By Roy's identity, given that the household has chosen bundle $i$ in (7), the four continuous demands are:

$$
\ln \left(V M T_{i 1}\right)=\alpha_{V 1}^{i}+\alpha_{p 1}^{i} p_{i 1}+\alpha_{p 2}^{i} p_{i 2}-\alpha_{q 1} q_{i 1}-\alpha_{q 2} q_{i 2}-\beta y+\beta_{1} k_{i}+x^{\prime} \gamma+\eta
$$

\footnotetext{
${ }^{18}$ Thus, a change in $p_{i}$ must have the same effect on Wear that it has on miles. We tried other models, including one where indirect utility has separate terms $\exp \left(\alpha_{p}^{i} p_{i}\right)$ and $\exp \left(\alpha_{q} q_{i}\right)$, so that $p_{i}$ would have no effect on Wear, and $q_{i}$ would have no effect on VMT. That model would not converge, and anyway it is restrictive by assuming no cross-price effects. We also tried models with more coefficients, to relax these restrictions, and we tried many starting points, but only the model in (4) and (5) could be estimated simultaneously for discrete and continuous choices (especially for two-vehicle bundles considered below).

${ }^{19}$ Another interesting question is about each household member's choice of miles driven (in either car), but we have no such data. As described below, we have only data on miles driven in each vehicle.
} 


$$
\begin{gathered}
\ln \left(\operatorname{VMT}_{i 2}\right)=\alpha_{V 2}^{i}+\ln \left(\alpha_{p 2}^{i} / \alpha_{p 1}^{i}\right)+\alpha_{p 1}^{i} p_{i 1}+\alpha_{p 2}^{i} p_{i 2} \\
-\alpha_{q 1} q_{i 1}-\alpha_{q 2} q_{i 2}-\beta y+\beta_{1} k_{i}+x^{\prime} \gamma+\eta \\
\ln \left(\text { Wear }_{i 1}\right)=\alpha_{W 1}^{i}+\ln \left(\alpha_{q 1} / \alpha_{p 1}^{i}\right)+\alpha_{p 1}^{i} p_{i 1}+\alpha_{p 2}^{i} p_{i 2} \\
-\alpha_{q 1} q_{i 1}-\alpha_{q 2} q_{i 2}-\beta y+\beta_{1} k_{i}+x^{\prime} \gamma+\eta \\
\ln \left(\text { Wear }_{i 2}\right)=\alpha_{W 2}^{i}+\ln \left(\alpha_{q 2} / \alpha_{p 1}^{i}\right)+\alpha_{p 1}^{i} p_{i 1}+\alpha_{p 2}^{i} p_{i 2} \\
-\alpha_{q 1} q_{i 1}-\alpha_{q 2} q_{i 2}-\beta y+\beta_{1} k_{i}+x^{\prime} \gamma+\eta
\end{gathered}
$$

These demands generalize those of a one-vehicle household in (5) by including terms for $p_{i 2}$ and $q_{i 2}$ (and so we refer to (8) for "all" demands). The demand for $V M T_{i 2}$ is symmetric to $V M T_{i 1}$ in explanatory variables, but it is non-linear in parameters of both $p_{i 1}$ and $p_{i 2}$. The demands for $\operatorname{Wear}_{i j}(j=1,2)$ are similarly defined.

\section{A Procedure to Estimate Discrete and Continuous Demands Simultaneously}

Note that the same parameters appear in both discrete and continuous choice functions, yet previous literature has estimated these choice models separately. Often the estimates for the same parameters are different not only in magnitude but also in sign. In this sub-section, we propose a procedure for simultaneous estimation of bundle choice, vehicle age, and miles driven. We start with separate discussion of car choice and miles driven, and then how we combine them in a single estimation procedure.

Following McFadden's random utility hypothesis, vehicle bundle $i$ is chosen if and only if: $V_{i} \geq V_{j}$ for all $j \neq i$. The unconditional expected share for bundle $i$ then is:

$$
S_{i}=\int \operatorname{Pr}\left(V_{i}>V_{j}, \forall j \neq i \mid \eta\right) f(\eta) d \eta
$$

where $S_{i}$ is the share choosing bundle $i$, and $f(\eta)$ is the probability density function of the agent-specific error $\eta$. We are now in a position to describe the importance of $\eta$. On the one hand, individual heterogeneity represented by $\eta$ could directly affect the choice of bundle. On the other hand, observed demands for VMT and Wear are conditional on that choice. Since the choice of vehicle bundle is endogenous, the estimated demands for $V M T$ and Wear could be biased if the influence of $\eta$ in (9) is ignored. In the model of Dubin and McFadden (1984), the error term $\eta$ can be cancelled out from the inequality $\left\{V_{i}>V_{j}, \forall j \neq i\right\}$, which simplifies the calculation of probabilities (that is, the integration 
over $\eta$ in equation (9) is not necessary). In such a model, $\eta$ appears only in the continuous demands, so this individual heterogeneity does not affect the choice of vehicle bundle directly. They can estimate the discrete model with error $\varepsilon_{i}$ for each bundle, and then, given predicted bundle shares, they estimate the continuous choices with errors $\eta$.

Yet, our purpose here is to retain individual-specific heterogeneity $\eta$ and its effect on bundle choice. Thus, the evaluation of probabilities in our model involves integration over all error components $(\varepsilon, \eta)$, where $\varepsilon=\left(\varepsilon_{1}, \varepsilon_{2}, \ldots, \varepsilon_{J}\right)$, and where $J$ is the number of possible vehicle bundles. In our model, the $\varepsilon_{i}$ are assumed to be distributed with a generalized extreme value (GEV) distribution, and $\eta$ follows an unknown distribution with a zero mean across individuals. Conditional on $\eta$, we integrate over the GEV distribution to obtain conditional choice probabilities as a general nested logit model:

$$
\operatorname{Pr}\left(V_{n i}>V_{l m}, \forall m \neq i, \forall n, l \mid \eta\right)=\frac{\exp \left(V_{i} / \lambda_{n}\right)\left(\sum_{j \in B_{k}} \exp \left(V_{j} / \lambda_{n}\right)\right)^{\lambda_{n}-1}}{\sum_{l=1}^{K}\left(\sum_{j \in B_{l}} \exp \left(V_{j} / \lambda_{l}\right)\right)^{\lambda_{l}}}
$$

where $n$ and $l$ represent nests, $i$ is an alternative within nest $n, m$ is an alternative within nest $l, K$ is the total number of nests, and $B_{l}(l=1, \ldots, K)$ represents a nested subset of alternatives. Our nesting structure is illustrated in Figure 1.

We also integrate over the distribution of $\eta$ to obtain unconditional probabilities. The literature offers no guidance on the distribution of the $\eta \cdot{ }^{20}$ To reduce the numerical difficulty in estimation, we let $\eta$ be uniformly distributed in the interval $[-\xi, \xi]$. We search for the $\xi$ that yields a likelihood function with the largest value. ${ }^{21}$

As pointed out by Dubin and McFadden (1984), the random error $\eta$ does not have a zero mean conditional on each chosen bundle, due to the endogeneity of bundle choice. This can be seen clearly if we rewrite equations (8a-d) into a more convenient form for estimation (using just equation $8 \mathrm{a}$, as an example):

$$
\begin{aligned}
\ln \left(V M T_{i 1}\right)= & \sum_{j} \alpha_{V 1}^{j} d_{i j}+\sum_{j} \alpha_{p 1}^{j} p_{j 1} d_{i j}+\sum_{j} \alpha_{p 2}^{j} p_{j 2} d_{i j} \\
& -\alpha_{q 1} \sum_{j} q_{j 1} d_{i j}-\alpha_{q 2} \sum_{j} q_{j 2} d_{i j}-\beta y+\beta_{1} \sum_{j} k_{j} d_{i j}+x^{\prime} \gamma+\eta
\end{aligned}
$$

\footnotetext{
${ }^{20}$ Dubin and McFadden (1984) assume $\eta$ has a particular form of mean and variance, in order to derive an explicit conditional expectation.

${ }^{21}$ This search yields $\xi$ equal to 0.65 . Since the estimation of the logit model requires integration over the individual heterogeneity term $\eta$, our model is a mixed logit model (McFadden and Train, 2000).
} 
where $d_{i j}$ is a choice indicator variable equal to one when $i=j$, and where equations (11b-d) are analogous. The random error $\eta$ is correlated with the choice indicators $d_{i j}$. Dubin and McFadden (1984) suggest sequential estimation to solve this endogeneity problem (a procedure later adopted by Goldberg (1998) and West (2004)). First, the discrete choice model is estimated and the predicted probabilities are calculated. They then suggest three alternative methods that yield consistent estimates of parameters for continuous demands: the instrumental variable method (IV), the reduced form method $(\mathrm{RF})$, and the conditional expectation correction method (CE). They derive the correction terms in terms of probabilities for the $\mathrm{CE}$ method based on the assumption of an i.i.d. extreme value distribution of $\varepsilon_{i}$. However, since we assume a GEV distribution of $\varepsilon_{i}$, these correction terms cannot be used in our model. We want a method that can be used both for sequential estimation and for our simultaneous estimation, in order to compare them, and so we employ the RF method. Taking expectation of (11a) over $\eta$, we have:

$$
\begin{aligned}
\ln \left(V M T_{n 1}\right) & =\sum_{j} \alpha_{V 1}^{j} S_{n j}+\sum_{j} \alpha_{p 1}^{j} p_{j 1} S_{n j}+\sum_{j} \alpha_{p 2}^{j} p_{j 2} S_{n j} \\
& -\alpha_{q 1} \sum_{j} q_{j 1} S_{n j}-\alpha_{q 2} \sum_{j} q_{j 2} S_{n j}-\beta y+\beta_{1} \sum_{j} k_{j} S_{n j}+x^{\prime} \gamma+u_{n 1}
\end{aligned},
$$

where $S_{n j}$ is the probability of individual $n$ choosing vehicle bundle $j$ from (9), $u_{n 1}$ is an additional error to represent the difference between observed $V M T$ and predicted $V M T$, and where (12b-d) are analogous (not shown here). The sequential RF method applies least squares to (12a-d), except that the shares $S_{n j}$ are replaced by estimated shares $\hat{S}_{n j}$ from the discrete choice model. In contrast, we estimate (9) and (12a-d) simultaneously.

Since the same parameters appear in both discrete and continuous choice functions, we propose a joint estimation method to capture this simultaneity. In particular, we obtain a set of parameters that maximize the following objective function:

$$
\begin{aligned}
& F\left(\Theta \mid y, p_{1}, p_{2}, q_{1}, q_{2}, k, x\right)=-\sum_{n}\left(\ln \left(V M T_{1}\right)-f_{1}\right)^{2}-\sum_{n}\left(\ln \left(V M T_{2}\right)-f_{2}\right)^{2}, \\
& -\sum_{n}\left(\ln \left(\text { Wear }_{1}\right)-g_{1}\right)^{2}-\sum_{n}\left(\ln \left(\text { Wear }_{2}\right)-g_{2}\right)^{2}+\sum_{n} \ln L
\end{aligned},
$$

where $f_{1}, f_{2}, g_{1}$, and $g_{2}$ represent the right hand sides (without the random error $u_{n 1}$ ) of the four equations $(12 \mathrm{a}-\mathrm{d}), \ln L$ is the $\log$ likelihood function of the nested logit, and $\Theta$ represents the set of parameters to be estimated by maximizing equation (13). 
As is consistent with Dubin and McFadden (1984) and other papers in this literature, the maintained hypotheses are that the utility functional form is correct and that consumers maximize it. Under these hypotheses, our procedure produces consistent estimates of parameters. The reasoning is as follows: if the components of (13) were maximized separately, and if some single set of parameters were the solution to all those separate maximizations, then this set of parameters would also maximize the combined objective function. To compare the results, we estimate our model by both the sequential method and the simultaneous estimation method.

\section{Elasticities}

Once we obtain the parameter estimates, we are ready to calculate elasticities. To see the marginal effects of prices on indirect utility, and therefore on bundle choice, we use equation (7) to obtain explicit formulas for those derivatives. First, define $\exp (\cdot) \equiv$ $\exp \left(\alpha_{p 1}^{i} p_{i 1}+\alpha_{p 2}^{i} p_{i 2}-\alpha_{q 1} q_{i 1}-\alpha_{q 2} q_{i 2}\right)$. Then:

$$
\begin{array}{ll}
\frac{\partial V_{i}}{\partial p_{i 1}}=-\exp (\cdot), & \frac{\partial V_{i}}{\partial p_{i 2}}=-\frac{\alpha_{p 2}^{i}}{\alpha_{p 1}^{i}} \exp (\cdot) \\
\frac{\partial V_{i}}{\partial q_{i 1}}=\frac{\alpha_{q 1}}{\alpha_{p 1}^{i}} \exp (\cdot), & \frac{\partial V_{i}}{\partial q_{i 2}}=\frac{\alpha_{q 2}}{\alpha_{p 1}^{i}} \exp (\cdot)
\end{array}
$$

and the marginal effects of income or capital cost on utility take similar forms:

$$
\begin{aligned}
& \frac{\partial V_{i}}{\partial y}=\exp \left(-\alpha_{0}^{i}+\beta y-\beta_{1} k_{i}-x^{\prime} \gamma-\eta\right) \\
& \frac{\partial V_{i}}{\partial k_{i}}=-\frac{\beta_{1}}{\beta} \exp \left(-\alpha_{0}^{i}+\beta y-\beta_{1} k_{i}-x^{\prime} \gamma-\eta\right)
\end{aligned}
$$

Then we derive the elasticity of choice $i$ with respect to a change in variable $z_{j}$ (where $z_{j}$ may be any of the price variables, income $y$, or capital cost $k_{j}$ ):

$$
\frac{\partial S_{i}}{\partial z_{j}} \cdot \frac{z_{j}}{S_{i}}=\frac{\partial S_{i}}{\partial V_{j}} \cdot \frac{\partial V_{j}}{\partial z_{j}} \cdot \frac{z_{j}}{S_{i}}
$$

Since these formulas involve the unconditional probability of vehicle bundle $i$, calculating each bundle elasticity requires integration over $\eta$. In contrast, calculations of VMT elasticites do not involve integration over $\eta$. For bundle $i(i=1, \ldots, 5)$, the ownand cross-price elasticities of VMT demand are calculated by: 


$$
e_{V 1 p 1}^{i}=\frac{\partial \ln \left(V M T_{i 1}\right)}{\partial \ln p_{i 1}}=\alpha_{p 1}^{i} p_{i 1}=e_{V 2 p 1}^{i}, \quad e_{V 2 p 2}^{i}=\frac{\partial \ln \left(V M T_{i 2}\right)}{\partial \ln p_{i 2}}=\alpha_{p 2}^{i} p_{i 2}=e_{V 1 p 2}^{i}
$$

The elasticities of demand for Wear with respect to its price have a similar form:

$$
e_{W 1 q 1}^{i}=\frac{\partial \ln \left(\text { Wear }_{i 1}\right)}{\partial \ln q_{i 1}}=-\alpha_{q 1} q_{i 1}=e_{W 2 q 1}^{i}, \quad e_{W 2 q 2}^{i}=\frac{\partial \ln \left(\text {Wear }_{i 2}\right)}{\partial \ln q_{i 2}}=-\alpha_{q 2} q_{i 2}=e_{W 1 q 2}^{i}
$$

We can also calculate the income elasticity, given by:

$$
e_{V y}^{i}=\frac{\partial \ln \left(V M T_{i 1}\right)}{\partial \ln y}=\frac{\partial \ln \left(V M T_{i 2}\right)}{\partial \ln y}=-\beta y,
$$

and the total capital cost elasticity, given by:

$$
e_{V k}^{i}=\frac{\partial \ln \left(V M T_{i 1}\right)}{\partial \ln k_{i}}=\frac{\partial \ln \left(V M T_{i 2}\right)}{\partial \ln k_{i}}=\beta_{1} k_{i} \text {. }
$$

In equations (16) - (20), elasticities are typically evaluated at each bundle's mean values of $y$ and $k$, the bundle average of gas prices per mile $\left(p_{1}\right.$ and $\left.p_{2}\right)$ and the bundle average of reimbursement prices $\left(q_{1}\right.$ and $\left.q_{2}\right)$.

\section{Data and Summary Statistics}

In order to analyze household choice of vehicles, miles driven, and vehicle Wear, we need micro-data on household characteristics, household income or expenditures, and detailed information about household-owned vehicles such as the number of vehicles, miles driven in each, and vehicle characteristics (including miles per gallon, MPG, and emissions per mile, EPM). No single data set contains all such information.

The Consumer Expenditure Survey (CEX) provides data on household income, characteristics, and household-owned vehicles. ${ }^{22}$ For each household, we aggregate expenditures over four quarters, taking demographic data and detailed vehicle information from their last quarter in the survey. We use the CEX from 1996 to 2000, supplemented with the corresponding OVB file (Owned Vehicles Part B Detailed questions). This OVB file includes data on each vehicle type, make, year, number of cylinders, purchase expenses and financing, time since purchase, mileage, gasoline expenditure, and other information. We keep only households that satisfy several criteria. First, expenditures

\footnotetext{
${ }^{22}$ The CEX data are collected by the Bureau of Labor Statistics of the U.S. Department of Labor through quarterly interviews of selected households throughout the U.S. Each household is interviewed over five consecutive quarters. Each quarter, $20 \%$ of households complete their last interview and are replaced by new households. For CEX data, see http://elsa.berkeley.edu or http://www.icpsr.umich.edu/.
} 
must be reported consecutively for four quarters in the CEX of 1996-2000. Second, the household must possess the same number of vehicles during these four quarters. Third, we remove households that own more than two vehicles. ${ }^{23}$ We also remove households that have vehicles other than automobiles or SUV's (defined to include light trucks or vans). Finally, we are left with 9027 households, of which 2077 own no vehicles, 4211 own one vehicle, and 2739 own two vehicles. We use yearly total expenditure as a proxy for yearly income of each household. Table 2 defines all the variables used in estimations.

Summary statistics are shown in Table 3 for major household characteristics by vehicle bundle. This table shows significant variations in household characteristics across the number of vehicles and bundles. For example, larger households especially with more kids have more vehicles and prefer SUVs. Wealthier households (as measured by total yearly expenditures) possess more vehicles. Households with more workers or income earners have more vehicles. Households with male heads are inclined to have SUVs.

Next, fuel price data are obtained from the ACCRA cost-of-living index for 19962000. This index compiles quarterly data for approximately 300 cities in the United States. It also lists average gasoline price for each city for each survey quarter. Since the CEX reports region and state of residence instead of city for each household, we average the city gas prices to obtain a state price for each calendar quarter. For those states reported in the CEX, but not reported in the ACCRA index, we use the average region price as a substitute. Then we assign a gas price to each CEX household based on the state of residence, CEX quarter, and year.

Some of the variables in our model require calculations or additional sources of data. We now describe these extra calculations.

(1) Wear: The vehicle's age is derived by taking the year of the survey minus the year the vehicle was made. We then assume $20 \%$ annual depreciation, and calculate Wear as the percentage of the vehicle's value that has wasted away (given all the vehicle characteristics unchanged except vehicle age). Wear ranges from zero for a new car, to Wear $=1$ for a very old car. Specifically, Wear $=1-(1-0.2)^{\text {age }}$.

(2) Capital value of the vehicle: The vehicle's year of purchase and reported purchase price $(p p)$ are available in the OVB file, but we want an estimate of current

\footnotetext{
${ }^{23}$ In the CEX of 1996-2000, 18.4\% of households own more than two vehicles. Some of these households may have a vehicle for business, whereas our model of household choice assumes utility maximization.
} 
market value $(\mathrm{cmv})$. We calculate the number of "years since purchase" (ysp), and we subtract depreciation for each year, again using $20 \%$ as the annual rate of depreciation. The formula is $c m v=p p \times(1-0.2)^{y s p}$. We then estimate a simple hedonic price regression:

$$
c m v=a_{0}+a_{1} c y l+a_{2} i m+b_{0}(1-\text { Wear })+b_{1}(\text { Wear } \times c y l)+b_{2}(\text { Wear } \times i m)
$$

where $a_{0}$ through $a_{2}$, and $b_{0}$ through $b_{2}$ are parameters. The variable $c y l$ denotes the number of cylinders, while $\mathrm{im}$ is a dummy variable indicating if the vehicle is imported. ${ }^{24}$ Wear is included in the regression to capture the effects of vehicle age on market value. Using a sub-sample of the CEX that has all necessary variables, we run separate regressions for cars and SUV's and report the results in Table 4. Then, for the value of each brand new "concept" vehicle (with Wear =0), we use:

$$
\hat{k}=\hat{a}_{0}+\hat{a}_{1} c y l+\hat{a}_{2} i m+\hat{b}_{0}
$$

where $\hat{a}_{0}$ through $\hat{a}_{2}$ and $\hat{b}_{0}$ are estimates of parameters in (21).

(3) The price of Wear: First, we calculate the extra amount paid for a car with no wear on it $($ Wear $=0)$ compared to a very old car with the same characteristics $($ Wear $=1)$. From $(21)$, that difference is $\left(\hat{b}_{0}-\hat{b}_{1} c y l-\hat{b}_{2} i m\right)$. Then, $q$ is the annual reimbursement price of Wear, that is, the amount saved during a year by an owner who accepts one whole unit of Wear (an old car instead of a new car). Since a very old car does not depreciate any further, the amount saved is the depreciation during the year from holding a new car. Again assuming $20 \%$ depreciation, we have: $q=0.2\left(\hat{b}_{0}-\hat{b}_{1} c y l-\hat{b}_{2} i m\right)$.

(4) Fuel Efficiency: The EPA reports miles per gallon (MPG) of new vehicles, but we need it for vehicles of all ages. The CEX does not contain this information, so we estimate MPG using data of the California Air Resources Board (CARB, 1997 and 2000). ${ }^{25}$ Their first sub-sample is "series 13", from November 1995 to March 1997, in which the CARB tested a total of 345 passenger cars, light-duty trucks, and medium-duty vans. The second sub-sample is "series 14", from November 1997 to August 1999, which includes

\footnotetext{
${ }^{24}$ The CEX does not include the vehicle's nation of origin, so we create the im dummy using information on manufacturer and model. We also tried other vehicle characteristics in the regression, such as indicators for automatic transmission, power steering, and air conditioning, but the estimates are not significant. Inclusion of these variables does not raise adjusted $\mathrm{R}^{2}$ and can result in negative predictions of $\mathrm{cmv}$.

${ }^{25}$ For MPG of new cars, http://www.fueleconomy.gov/feg/index.htm is a website of the US Environmental Protection Agency (EPA) and the Department of Energy. The EPA also provides the historical fuel economy of new vehicles at http://www.epa.gov/otaq/mpg.htm or at http://www.epa.gov/otaq/tcldata.htm.
} 
332 vehicles (but which reports only 327 vehicles). In total, we use 672 vehicles. We regress MPG against vehicle characteristics in the CARB and then use those estimated coefficients to predict MPG for each vehicle in the CEX. The estimation results are shown in Table 5, where a 4-cylinder SUV is the omitted category. This table shows that fuel efficiency decreases with vehicle age and with engine size, both for cars and for SUV's. Given the same vehicle age and engine size, MPG is higher for cars than for SUV's.

(5) Emissions per mile (EPM): For the same sample of 672 used vehicles, the CARB tests for several pollutants. Following Fullerton and West (2000), we weight each pollutant by estimates of its damages, with the highest weight on nitrous oxides $\left(\mathrm{NO}_{\mathrm{X}}\right.$, $0.495)$, followed by hydrocarbons ( $\mathrm{HC}, 0.405)$, and carbon monoxide $(\mathrm{CO}, 0.10)$. Results appear in Table 5. Cars pollute less than SUV's because they were produced under stricter standards. Older vehicles pollute more, both because newer vintages faced stricter standards and because pollution control equipment deteriorates over time. ${ }^{26}$

(6) Vehicle Miles Traveled (VMT): The OVB file provides cumulative miles on each vehicle, but we need yearly miles driven. We had planned to match households across quarters, take the latest odometer reading minus the earliest one, divide by the number of quarters between readings, and multiply by four. Unfortunately, however, some later odometer readings are less than the earlier ones, and many readings are missing. Therefore, we propose a different procedure to get $V M T$. For a one-car household, we take observed annual expenditure on gasoline, divide by the price per gallon to get number of gallons, and then multiply by MPG to get miles. For a two-vehicle household, we only know the total gasoline expenditure, so we need to allocate it between the two vehicles. Only for this allocation do we use the difference in odometer readings between quarters. ${ }^{27}$

(7) Vehicle bundles: As listed in Table 1, vehicle choices are classified into six categories according to the number and type of vehicles. For bundle 4, with one car and one SUV, the car is always identified as the first vehicle. For bundles 3 and 5, the first vehicle is identified as the one with higher yearly VMT. If two vehicles have the same

\footnotetext{
${ }^{26}$ For vehicles in our sample, the calculated $E P M$ is 1.89 grams/mile for the average car and 3.56 for the average SUV. It also increases to 6.94 grams/mile for a very old vehicle (with Wear =1).

${ }^{27}$ If the difference in odometer readings is positive for both vehicles, then we divide it by MPG to obtain an estimate of each vehicle's gas consumption. Each gasoline amount divided by their sum gives shares, used to allocate the observed total gas consumption. Each vehicle's gallons divided by MPG yields VMT. If the difference in odometer readings is positive only for one vehicle, we use this figure as $V M T_{1}$ and calculate gasoline used in this vehicle. Then total gasoline minus gas used in this vehicle is residual gas, allocated to the other vehicle. Dividing this residual gas by MPG yields $V M T_{2}$. If the difference in odometer readings is positive for neither vehicle, then we do imputations based on households with similar characteristics.
} 
yearly $V M T$, the identification is random. If $V M T$ is missing, then the vehicle with an earlier purchase year is taken as the first vehicle. If the purchase year and miles-driven are both missing, the identification is random.

\section{Estimation Results}

The model described in Section I is estimated by both the sequential and the simultaneous estimation methods. The mean values of key variables are reported by bundle in Table 6. We average the values within each bundle for each bundle-specific variable except gas price per mile. Gas price per mile is calculated by dividing gas price per gallon by a bundle-specific MPG listed in Table 1. Thus, gas prices per mile vary both within and between bundles. The presence of collinearity between the fixed effects $\alpha_{0}^{i}(i$ $=1, \ldots, 6)$ and the bundle-specific variables such as $k_{i}(i=1, \ldots, 5)$ forces us to normalize the fixed effect of bundle one $\left(\alpha_{0}^{1}\right)$ to zero. To facilitate the estimation, we also normalize $y$ in units of 10,000 dollars, $k_{i}$ in units of 1,000, and $q_{1}$ and $q_{2}$ in units of 100 dollars. Accordingly, we multiply Wear $_{1}$ and Wear 2 by 100 to keep the total amount of reimbursement unchanged in the budget constraint.

Notice that bundle 3 and bundle 5 each contains two vehicles of the same type, while bundle 4 consists of one car and one SUV. When the retail gas price increases, all gas prices per mile are affected in bundle-specific ways because MPG depends both on vehicle age and type (car or SUV). As revealed by Table 1, MPG is more type-specific than bundle-specific. Thus, we expect that the gas price parameters of car bundles 1 and 3 are quite close to one another, as are those of SUV bundles 2 and 5. For a household with one car and one SUV (bundle 4), however, we wish to allow more substitution. In our estimation, we assign one parameter $\alpha_{C 1}$ to the gas price of the only car in bundle 1 and first car in bundle 3 (and $\alpha_{C 2}$ to the second car). We assign one parameter $\alpha_{S 1}$ to the only SUV in bundle 2 and first SUV of bundle 5 (and $\alpha_{S 2}$ to the second SUV). Then we assign two gas price parameters to bundle 4: $\alpha_{p 1}^{4}\left(=\alpha_{C A R}^{4}\right)$ for the car and $\alpha_{p 2}^{4}\left(=\alpha_{S U V}^{4}\right)$ for the SUV. Results from the sequential estimation are discussed first.

We follow the procedure suggested by Dubin and Mcfadden (1984), but at the first stage we estimate a nested logit structure instead of a multinomial logit model. The traditional ML method is employed. The RF method is adopted at the second stage because the correction terms derived by Dubin and Mcfadden are inappropriate for the 
GEV error structure. In the second stage we estimate four continuous demand equations jointly (only two equations for the one-vehicle bundles), using an objective function similar to equation (13) except that the last term is removed. We constrain parameters to be constant across bundles except those for gas prices and constant terms. The estimation results are reported in the first two columns of Table 7, under "sequential estimation".

For the discrete choice model in the first column of Table 7, the estimates of $\alpha_{C 1}$ and $\alpha_{S 1}$ are significant at the $1 \%$ level, while those of $\alpha_{C 2}$ and $\alpha_{S 2}$ are not statistically significant. The estimates of $\alpha_{p 1}^{4}\left(=\alpha_{C A R}^{4}\right)$ and $\alpha_{p 2}^{4}\left(=\alpha_{S U V}^{4}\right)$ are both significant at the 0.01 level. All of them are negative as expected. The Wear coefficients $\alpha_{q 1}$ and $\alpha_{q 2}$ are also different from zero at the 0.01 level. The parameter $\lambda_{n}(n=1,2)$ measures the degree of independence of the errors of alternatives in nest $n$. In our model, the estimates of $\lambda_{l}$ and $\lambda_{2}$ are 0.814 and 0.066 , respectively, both significant at the 0.01 level. ${ }^{28}$

Since all the estimates of $\alpha_{p 1}$ and $\alpha_{p 2}$ are negative, equations (14) indicate that the marginal effects of gas prices per mile are negative. As consistent with expectation, an increase in gas price reduces household utility. Since the coefficient on the reimbursement price $q_{1}$ is negative, the marginal effect on utility is positive as expected. A higher reimbursement price means more money back to the household for accepting a given vehicle age or level of Wear. However, the coefficient on $q_{2}$ has unexpected sign. Since estimates of $\beta$ and $\beta_{1}$ are both negative and significant, equations (15) indicate that the marginal effect of capital cost is negative while that of income is positive.

We then use those discrete choices from the first column to estimate the continuous demands shown in the second column. A glance down the second column indicates that most of estimated coefficients are quite different from the corresponding estimates in the first column. Yet the parameters in the second column are the same parameters as in the first column, even from the same model, as the continuous demands are supposed to be consistent with a particular indirect utility function. For example, the estimated coefficient on income is -1.408 in the first column and +1.134 in the second column. Both have small errors, and so they are significantly different from each other, even though they are the

\footnotetext{
${ }^{28}$ If $\lambda_{n} \forall n$ are within the range of zero to one, then "the model is consistent with utility maximization for all possible values of the explanatory variables" (Train, 2003, p.85). Since our $\lambda$ are significantly less than one, the errors within each nest are correlated, evidence in favor of nesting rather than MNL.
} 
same parameter of the same model. Many price coefficients also differ significantly in magnitude (and the two estimates of $\alpha_{q 2}$ differ in sign).

Next, the model is estimated by the simultaneous estimation procedure proposed in Section I.C. The point of this procedure is to capture household-specific heterogeneity in both discrete and continuous choices. The two types of choices are connected by the same parameters and the same random error term $\eta$ appearing in both. ${ }^{29}$ In contrast, in the sequential procedure, the bundle choice affects continuous demands (and not vice versa). The simultaneous estimates are reported in the last column of Table 7.

All ten estimates of coefficients on key variables have the expected signs, and all but two are significantly different from zero. Yet, for many parameters, the estimate differs from both estimates obtained by sequential estimation. For example, the capital cost coefficient $\left(\beta_{1}\right)$ from the simultaneous model $(-0.405)$ is smaller in magnitude than either that of the logit model $(-0.671)$ or the continuous demand model $(-0.456)$. The estimates of coefficients on demographic variables vary with the estimation method, not only in magnitude but also in sign. For most price variables, however, the estimate from the simultaneous model is between the two estimates from sequential estimation, which suggests that the simultaneous model might provide more "reasonable" coefficients. These coefficients cannot really be compared directly, however, and so we turn to elasticities.

\section{Elasticity Comparisons}

Bundle choice elasticities are presented in Table 8. The upper panel shows elasticities from the sequentially estimated model, but our discussion will start with the elasticities in the lower panel from the simultaneously estimated model. Each entry in the table is not an elasticity with respect to each price in the model, as it might be difficult to interpret an elasticity such as the change in the probability of holding bundle 3 (two cars) for a change in the price $p_{1}$ for gas in the first car only. Instead, we calculate the simultaneous effect on all choices for a change in the price of gasoline. In the lower part of Table 8 , the first row shows that a $1 \%$ increase in the price of gas would decrease most the probability of holding bundle 4 with a car and an SUV (by $0.793 \%$ ) while increasing the share holding bundle 3 with two cars (by 0.695\%). In other words, these households

\footnotetext{
${ }^{29}$ The standard deviation for $x^{\prime} \gamma$ is about 0.086 within a bundle, and for $\beta y$ is about 0.78 within a bundle, so the finding that $\eta$ has a range $(-0.65,0.65)$ reflects a significant amount of individual heterogeneity. Therefore, introducing individual heterogeneity is expected to make a difference in parameter estimates.
} 
sell the SUV for a second car instead. This change is driven by the high price of driving an SUV with low fuel efficiency. ${ }^{30}$ In contrast, using results from the sequential method in the top panel, the price of gas has little effect on any bundle share.

Given vehicle age, a higher reimbursement price $q$ for Wear of a particular bundle means more money back to the household and thus higher probability of choosing that bundle. Again, however, it is difficult to interpret a change in the price $q_{1}$ for the first car with no change in $q_{2}$ for the household's second car. Instead, we show effects of a change in $q$ for all vehicles (or for all cars only, or all SUV's only). Rather than raising $q$, policymakers may want to reduce $q$ by taxing old vehicles or by subsidizing the purchase of a new vehicle, in order to reduce emissions. Table 5 above shows that emissions per mile (EPM) are higher for SUV's than for cars, and rise with either vehicle's age.

For the simultaneous model in the lower part of Table 8, the second row shows that a $1 \%$ tax on Wear (lower $q$ for all vehicles) would decrease the probabilities of holding all bundles except bundle 5 (SUV, SUV). In the next row, a tax on the age only of cars would decrease the reimbursement for wear on cars, $q_{c a r}$, and switch households out of cars and into bundle 2 with an SUV and bundle 5 with two SUV's. Conversely, the next row shows that a tax on the age only of SUV's that lowers $q_{\text {suv }}$ would induce a switch out of bundles 2 and 5 with just SUV's, and into bundles with cars. ${ }^{31}$

The discrete-choice-only model in the top half of the table shows results for $q$ where effects on SUV bundles are unreasonably large and sometimes the wrong sign. A tax that lowers $q_{s u v}$ would encourage the purchase of two SUV's.

Back to the lower panel for the simultaneous model, the choice elasticities with respect to $y$ indicate that households with more income switch from holding no car (bundle 6) to one car (bundle 1), and those with a single SUV (bundle 2) seem to add a car (bundle 4). Additional income reduces the share with two cars (bundle 3). These results are inconsistent with the discrete-choice model, where the only bundle with a positive income elasticity is bundle 2 with one SUV.

\footnotetext{
${ }^{30}$ This reasoning is confirmed by the choice elasticities with respect to $p_{1}$ and $p_{2}$ separately. For bundle 4, a $1 \%$ higher price per mile in the car reduces the probability of choosing that bundle by $0.37 \%$, while a $1 \%$ higher price per mile in the SUV $\left(p_{2}\right)$ reduces the probability of choosing that bundle by $0.81 \%$. Thus, the gas consumption of the SUV has twice as much impact as that of the car.

${ }^{31}$ This tax on age of SUV's might actually cut emissions in two ways: by inducing a switch from SUV's to cars (Table 8), and by inducing a switch from older SUV's to newer SUV's (Table 9 below).
} 
We next look at an increase in capital cost in the lower panel of Table 8. Since this change effectively reduces available income, we see that each capital cost elasticity has the opposite sign as that bundle's income elasticity. With higher capital costs, households seem to shift primarily out of two-vehicle bundles with at least one SUV (4 and 5) into bundles with two cars (bundle 3) or only one SUV (bundle 2). While it does not make sense to increase the capital cost only for the first car of a two-car household, it might make sense to increase the capital cost only of cars relative to SUV's or vice versa (to represent a vehicle-type tax). The next row of Table 8 shows that if the increase in capital cost pertains only to cars, then it decreases the shares of the two bundles that have only cars. If it pertains only to SUV's, however, then it has large effects that decrease the shares of all three bundles with SUV's. Such a policy could clearly reduce emissions (given the EPM in Table 5). The 1\% higher cost of an SUV means $13.7 \%$ less of bundle 4, which seems too large, but it means that the share falls two percentage points (from $14.5 \%$ of all households in Table 6 to $12.5 \%$ of all households). The discrete-choice-only model in the top part of Table 8 produces elasticities with smaller magnitudes, except that the bundle 5 elasticity has the wrong sign (higher $k_{s u v}$ lead to more households with two SUV's).

The sequential model uses predictions of discrete choices to estimate continuous demands, for which elasticities are shown in the top half of Table 9. These are "short run" elasticities, in the sense that car choices are fixed and only continuous choices like driving distances may change (Goldberg, 1998). ${ }^{32}$ Again, we focus primarily on simultaneously estimated elasticities in the bottom panel. In the first row, all elasticities for $V M T_{1}$ with respect to gasoline price are negative, as expected, for all bundles. (For this demand, the sequential model produces similar results.) The next row of Table 9 shows the effects of a $1 \%$ increase in the reimbursement price, $q$, on Wear. These elasticities are all positive, as expected: households choose older vehicles when they get higher reimbursement for holding an old vehicle. Conversely, a tax on vehicle age that reduces $q$ by $10 \%$ would reduce desired Wear by about 1.2 to $1.4 \%$ (assuming the desired cars were available). ${ }^{33}$ The table also shows similar effects of changing $q$ just for cars, or just for SUV's.

Next, consider income and capital cost elasticities. Due to the symmetric specification of demand functions, a $1 \%$ change in $y$ or $k$ has the same effect on both

\footnotetext{
${ }^{32}$ Panel data would be required to distinguish the effects of lags from contemporaneous price changes.

${ }^{33}$ In Table 6, the average Wear of 0.75 corresponds to 6.2 years of age, so a $1.2 \%$ decrease in Wear means a decrease of about one month of age. In the sequential model, the same $10 \%$ lower $q$ affects desired age of one-vehicle bundles by one-tenth as much, and desired ages of two-vehicle bundles by three times as much.
} 
$V M T$ and Wear (whether for the first vehicle or the second). In the simultaneous model, income elasticities are positive as expected. One percent more income would increase driving distances by about $1 \%$ to $1.5 \%$ for all bundles. In contrast, the sequential model implies income elasticities that are all negative and large (-2.6 to -4.0$)$. The capital cost elasticities are negative as expected, for both models.

The specific form for utility in equation (4) means a specific form for demands in equations (5), where $\ln (V M T)$ and $\ln ($ Wear $)$ both depend on $\alpha_{p}^{i} p_{i}-\alpha_{q} q_{i}$. In other words, the parameter that determines the important effect of gas price on miles $\left(\alpha_{p}^{i}\right)$ also necessarily drives the less-important effect of the gas price on choice of Wear. Similarly, the own-price effect of $q$ on Wear also drives the cross-price effect of $q$ on $V M T$. We note this fact, but we do not mean to emphasize these cross-price elasticities.

Finally, the last column in Table 9 reports the percentage change in total emissions when each variable increases by $1 \%$. In the simultaneous model, for example, a $1 \%$ increase in all gasoline prices would reduce total emissions by $0.136 \%$, while a tax on age that reduces $q$ by $1 \%$ would reduce total emissions by $0.434 \% .^{34}$ The largest elasticities are from income and capital cost: $1 \%$ higher income raises total emissions as expected, by $4.246 \%$ (but in the sequential model would reduce emissions by $11.47 \%$ !) A $1 \%$ increase in capital cost reduces total emissions by about $8 \%$ in either model.

In the simultaneously estimated model, the coefficients are affected by all discrete and continuous choices. The model imposes more constraints on the estimates. Thus, if those constrained estimates are plugged into the likelihood function for either part of the sequential procedure, then the likelihood is not as high as for that portion of the sequential procedure. However, the sequentially estimated model yields two sets of estimates for the same parameters. The finding that these estimates are not consistent with each other raises questions about whether the behavioral model is correctly specified.

\section{Conclusion}

This paper focuses on incentive effects of price changes that might be associated with policies to reduce vehicle emissions. We provide a model of household behavior that incorporates both the discrete choice of vehicle type, with different fuel efficiencies and

\footnotetext{
${ }^{34}$ These are also short run elasticities, with no change in the number or type of vehicles. Notice that the percentage change in emissions from a change in $p$ is more than twice the change in driving distance, because the higher $p$ also reduces demand for Wear (which also reduces emissions). The change in $q$ also affects both VMT and Wear in the same direction, enlarging the effect on emissions.
} 
emission rates, and continuous demands for miles driven. Because emission rates depend directly on vehicle age, we also model vehicle age as a continuous choice. To model the effect of prices on the choice of vehicle age, we establish a choice of "concept vehicle" that is separate from the choice of "Wear". Using hedonic price regressions, we quantify the price of Wear. Then, after the discrete choice among concept vehicles, both VMT and Wear become continuous variables that enter utility.

Yearly household data are obtained from the CEX of 1996 - 2000, supplemented with fuel efficiency estimates from the CARB, and gas prices from the ACCRA cost of living indexes. First, like many others, we follow the sequential procedure suggested by Dubin and McFadden (1984). This procedure generates two different sets of estimates for the same set of parameters, which we argue is inconsistent with maintained hypotheses about the utility function and utility maximization. We then propose and implement a simultaneous method for consistent estimation of both discrete and continuous choices in one step. Results from the simultaneous estimation differ significantly both in signs and magnitude from both sets of estimates obtained by sequential estimation.

We find that a higher price of gasoline would shift households out of the Car-SUV pair and into the bundle with two cars. It also would reduce miles driven. Both of these changes reduce emissions. A tax on vehicle age would induce shifts to newer vehicles with less "Wear", and would also shift families out of bundles with an SUV. Both of these changes also reduce emissions. Similarly, a tax on SUV's would shift families into cars and reduce emissions. The size of these shifts is important information for environmental policy. Rather than pin down the exact size of the important parameters, however, this paper points to important problems with existing methods and suggests an alternative approach with more internal consistency.

\section{References}

Bento, Antonio, Lawrence Goulder, Emeric Henry, Mark Jacobsen, and Roger von Haefen. "Efficiency and Distributional Impacts of U.S. Policies to Reduce Automobile Pollution", Working Paper, Department of Economics, Stanford University (2005).

Bhat, Chandra. "A Multiple Discrete-Continuous Extreme Value Model: Formulation and Application to Discretionary Time-Use Decisions," Working Paper, Department of Civil Engineering, University of Texas at Austin (2005).

Brownstone, David and Kenneth Train. "Forecasting New Product Penetration with Flexible Substitution Patterns," Journal of Econometrics 89 (1999), 109-29. 
Brownstone, D., D.S. Bunch, T.F. Golob, and W. Ren. "A Vehicle Transactions Choice Model for Use in Forecasting Demand for Alternative-Fuel Vehicles," Research in Transportation Economics 4 (1996), 87-129.

California Air Resources Board. Test Report of the Light-Duty Vehicle Surveillance Program, Series 13, Project Number 2S95C1 (September 1997).

California Air Resources Board. Report of the Results of the Vehicle Surveillance Program 14, Project Number 2S97C1 (March 2000).

Dubin, Jeffrey and Daniel McFadden. "An Econometric Analysis of Residential Electric Appliance Holdings and Consumption," Econometrica 52:2 (March 1984), 345-62.

Eskeland, Gunnar and Shantayanan Devarajan. Taxing Bads by Taxing Goods: Pollution Control with Presumptive Charges, Washington, DC: The World Bank (1996).

Fullerton, Don and Sarah West. "Tax and Subsidy Combinations for the Control of Vehicle Pollution,” NBER Working Paper No. 7774, Cambridge, MA (2000).

Fullerton, Don and Sarah West. "Can Taxes on Vehicles and on Gasoline Mimic an Unavailable Tax on Emissions?" Journal of Environmental Economics and Management 43 (January 2002), 135-57.

Goldberg, Pinelopi. "The Regulation of Fuel Economy and the Demand for 'Light Trucks'," Journal of Industrial Economics 46:1 (March 1998), 1-33.

Greene, David L. and Patricia Hu. "The Influence of the Price of Gasoline on Vehicle Use in Multi-vehicle Households," Transportation Research Record 988 (1985), 19-24.

Hanemann, W. Michael. "Discrete/Continuous Models of Consumer Demand," Econometrica 52:3 (May 1984), 54-62.

Harrington, Winston and Virginia McConnell. "Motor Vehicles and the Environment," in H. Folmer and T. Tietenberg, eds., The International Yearbook of Environmental and Resource Economics 2003/2004, Northampton, MA: Edward Elgar (2003).

Hausman, Jerry A. "Exact Consumer's Surplus and Deadweight Loss," American Economic Review 71:4 (September 1981), 662-76.

Heeb, Norbert, Anna-Maria Forss, Christian Saxer, and Patrick Wilhelm. "Methane, Benzene and Alkyl Benzene Cold Start Emission Data of Gasoline-Driven Passenger Cars Representing the Vehicle Technology of the Last Two Decades," Atmospheric Environment 37 (2003), 5185-95.

Hulten, Charles R. and Frank C. Wykoff. "Issues in the Measurement of Economic Depreciation," Economic Inquiry 34 (January 1996): 10-23.

Innes, Robert. "Regulating Automobile Pollution Under Certainty, Competition, and Imperfect Information," Journal of Environmental Economics and Management 31 (September 1996), 219-39.

Jorgenson, Dale W. "Empirical Studies of Depreciation." Economic Inquiry 34 (January 1996), 24-42.

Kohn, Robert E. "An Additive Tax and Subsidy for Controlling Automobile Pollution." Applied Economics Letters 3 (July 1996), 459-62. 
Mannering, Fred and Winston, Clifford. "A Dynamic Empirical Analysis of Household Vehicle Ownership and Utilization," Rand Journal of Economics 16:2 (Summer 1985), 215-36.

McFadden, Daniel. "Quantitative Methods for Analyzing Travel Behavior of Individuals: Some Recent Developments," in David Hensher and P. Stopher, eds., Behavioral Travel Modeling, London: Croom Heml (1979), 279-318.

McFadden, Daniel. "Disaggregate Behavioural Travel Demand's RUM Side: A 30-Year Retrospective," in Hensher, ed., Travel Behavior Research: The Leading Edge. London: Pergamon (2001).

McFadden, Daniel and Kenneth Train. "Mixed MNL Models for Discrete Response," Journal of Applied Econometrics 15:5 (2000), 447-70.

Newell, Richard G. and Robert N. Stavins, "Cost Heterogeneity and the Potential Savings from Market-Based Policies," Journal of Regulatory Economics 23:1 (January 2003), 43-59.

Plaut, Pnina. "The Comparison and Ranking of Policies for Abating Mobile-Source Emissions," Transportation Research D 3 (July 1998), 193-205.

Pigou, Arthur C. The Economics of Welfare, London: MacMillan (1920).

Sevigny, Maureen. Taxing Automobile Emissions for Pollution Control. Cheltenham, UK and Northhampton, MA: Edward Elgar Publishing Ltd. (1998).

Sierra Research. "Analysis of the Effectiveness and Cost-Effectiveness of Remote Sensing Devices." Report SR94-05-05, prepared for the U.S. Environmental Protection Agency, Sacramento, CA: Sierra Research (1994).

Train, Kenneth. Qualitative Choice Analysis: Theory, Econometrics, and an Application to Automobile Demand, Cambridge, MA: The MIT Press (1986).

Train, Kenneth. Discrete Choice Methods with Simulation, Cambridge, United Kingdom: Cambridge University Press (2003).

Train, Kenneth, William B. Davis and Mark D. Levine. "Fees and Rebates on New Vehicles: Impacts on Fuel Efficiency, Carbon Dioxide Emissions, and Consumer Surplus," Transportation Research E 33 (1997), 1-13.

U.S. Environmental Protection Agency. Technical Methods for Analyzing Pricing Measures to Reduce Transportation Emissions, Washington, DC (1998).

West, Sarah. "Distributional Effects of Alternative Vehicle Pollution Control Policies," Journal of Public Economics 88:3-4 (March 2004), 735-57. 
Table 1. Vehicle Bundle Descriptions and Statistics

\begin{tabular}{ccccccc}
\hline Bundle & $\begin{array}{c}\text { \# of } \\
\text { Vehicles }\end{array}$ & $\begin{array}{c}\text { First } \\
\text { Vehicle }\end{array}$ & $\begin{array}{c}\text { Second } \\
\text { Vehicle }\end{array}$ & $\begin{array}{c}\text { \# of } \\
\text { Households }\end{array}$ & $\begin{array}{c}\text { MPG of } \\
\text { First } \\
\text { Vehicle }\end{array}$ & $\begin{array}{c}\text { MPG of } \\
\text { Second } \\
\text { Vehicle }\end{array}$ \\
\hline 1 & 1 & Car & -- & 3469 & 21.37 & -- \\
3 & 1 & SUV & -- & 742 & 16.76 & -- \\
4 & 2 & Car & Car & 1181 & 21.88 & 21.55 \\
5 & 2 & Car & SUV & 1305 & 21.51 & 16.53 \\
6 & 2 & SUV & SUV & 253 & 17.04 & 16.50 \\
\hline
\end{tabular}

Note: The number of households is from the consumer expenditure survey (CEX), and miles per gallon (MPG) is calculated from CARB data described below. 
Table 2. Variable Definitions

\begin{tabular}{|c|c|}
\hline Variable & Definition \\
\hline$y$ & Household's yearly expenditure \\
\hline$k$ & Total capital cost of a vehicle bundle \\
\hline$p_{1}$ & Gas price per mile of the first vehicle \\
\hline$p_{2}$ & Gas price per mile of the second vehicle \\
\hline$q_{1}$ & Unit price of Wear of the first vehicle \\
\hline$q_{2}$ & Unit price of Wear of the second vehicle \\
\hline$V M T_{1}$ & Miles driven in the first vehicle \\
\hline$V M T_{2}$ & Miles driven in the second vehicle \\
\hline Wear $_{1}$ & Continuous variable to measure the wear of the first vehicle \\
\hline Wear $_{2}$ & Continuous variable to measure the wear of the second vehicle \\
\hline Famsize & Number of members in a household \\
\hline Earnr & Number of income earners in a household \\
\hline Kids & Number of children less than 18 in a household \\
\hline Drivers & Number of household members 16 years old and over \\
\hline Metro & $\begin{array}{l}\text { A dummy variable: one if the household resides inside a } \\
\text { Metropolitan Statistical Area (MSA), and zero otherwise }\end{array}$ \\
\hline Pop4 & $\begin{array}{l}\text { A dummy variable: one if the household lives in an area with a } \\
\text { population of more than } 4 \text { million, and zero otherwise }\end{array}$ \\
\hline Urban & $\begin{array}{l}\text { A dummy variable: one if the household lives in an urban area, } \\
\text { and zero otherwise. }\end{array}$ \\
\hline Age & Age of household head \\
\hline White & $\begin{array}{l}\text { A dummy variable: one if the household head is white, and } \\
\text { zero otherwise }\end{array}$ \\
\hline Male & A dummy variable: one if the head is male, zero otherwise \\
\hline Educ & $\begin{array}{l}\text { A dummy variable: one if the head has education higher than } \\
\text { high school, zero otherwise }\end{array}$ \\
\hline Northwest & A dummy variable: one if in the Northwest, zero otherwise \\
\hline Midwest & A dummy variable: one if in the Midwest, zero otherwise \\
\hline South & A dummy variable: one if in the South, zero otherwise \\
\hline West & A dummy variable: one if in the West, zero otherwise \\
\hline
\end{tabular}


Table 3. Summary of Household Statistics by Vehicle Bundles

\begin{tabular}{c|cc|cccc}
\hline \multirow{2}{*}{ Characteristics } & \multicolumn{7}{|c}{ Number of Vehicles } \\
\cline { 2 - 7 } & 1 (Car) & 2 (SUV) & $3(\mathrm{C}, \mathrm{C})$ & $4(\mathrm{C}, \mathrm{S})$ & $5(\mathrm{~S}, \mathrm{~S})$ & 6 (none) \\
\cline { 2 - 7 } & 3469 & 742 & 1181 & 1305 & 253 & 2077 \\
\hline \# of households & 1.92 & 2.30 & 2.65 & 2.94 & 3.44 & 1.98 \\
household size & 23.87 & 33.56 & 33.62 & 43.98 & 62.45 & 26.05 \\
\% with kids & 0.44 & 0.73 & 0.56 & 0.89 & 1.42 & 0.55 \\
\# of kids & 1.52 & 1.63 & 2.13 & 2.12 & 2.13 & 1.48 \\
\# 15 years old & 0.85 & 1.08 & 1.43 & 1.49 & 1.58 & 0.70 \\
\# of workers & 40.10 & 63.07 & 65.54 & 71.80 & 77.47 & 33.22 \\
\% heads male & 55.24 & 48.22 & 51.84 & 49.45 & 45.24 & 55.66 \\
age of head & 82.07 & 87.60 & 83.32 & 89.04 & 92.89 & 67.89 \\
\% heads white & 82.04 & & \\
\% heads educ $>$ & 52.15 & 52.29 & 66.05 & 57.01 & 57.31 & 34.33 \\
high school & & & & & & \\
\% in area with & 28.37 & 19.41 & 30.48 & 22.68 & 18.58 & 38.61 \\
pop.> 4 million & & & & & & \\
expenditures & 22754. & 24574. & 35472. & 33812. & 34246. & 17795. \\
total gas cost & 648. & 920. & 1103. & 1279. & 1398. & -- \\
\hline
\end{tabular}

Table 4. Hedonic Price Regressions

\begin{tabular}{|c|c|c|c|c|}
\hline \multirow{2}{*}{$\begin{array}{c}\text { Dependent } \\
\text { Variable: } c m v\end{array}$} & \multicolumn{2}{|c|}{ Cars } & \multicolumn{2}{|c|}{ SUVs } \\
\hline & Coefficient & $\begin{array}{l}\text { Standard } \\
\text { Error }\end{array}$ & Coefficient & $\begin{array}{l}\text { Standard } \\
\text { Error }\end{array}$ \\
\hline constant $\left(a_{0}\right)$ & 1444.64 & 1806.08 & -1220.52 & 2702.42 \\
\hline $\operatorname{cyl}\left(a_{1}\right)$ & 3150.55 & 288.44 & 1993.56 & 411.23 \\
\hline $\operatorname{import}\left(a_{2}\right)$ & 2371.11 & 894.32 & 1417.36 & 1584.27 \\
\hline $1-$ Wear $\left(b_{0}\right)$ & -2179.03 & 3272.66 & 8973.32 & 4996.71 \\
\hline Wear×cyl $\left(b_{1}\right)$ & -3184.92 & 546.49 & -1459.66 & 763.85 \\
\hline Wearximport $\left(b_{2}\right)$ & -998.07 & 1719.28 & -658.35 & 2800.80 \\
\hline $\mathrm{R}^{2}$ & \multicolumn{2}{|c|}{0.49} & \multicolumn{2}{|c|}{0.51} \\
\hline \# of obs. & \multicolumn{2}{|c|}{793} & \multicolumn{2}{|c|}{510} \\
\hline
\end{tabular}


Table 5: Estimation of Miles Per Gallon (MPG) and Emissions Per Mile (EPM)

\begin{tabular}{|c|c|c|c|c|}
\hline \multirow{3}{*}{$\begin{array}{c}\text { Independent } \\
\text { Variable }\end{array}$} & \multicolumn{4}{|c|}{ Dependent Variable } \\
\hline & \multicolumn{2}{|c|}{ MPG } & \multicolumn{2}{|c|}{ EPM } \\
\hline & Coefficient & $\begin{array}{l}\text { Standard } \\
\text { Error }\end{array}$ & Coefficient & $\begin{array}{l}\text { Standard } \\
\text { Error }\end{array}$ \\
\hline constant & 24.021 & 0.496 & -0.597 & 0.663 \\
\hline cyl6 & -4.395 & 0.483 & 1.103 & 0.645 \\
\hline cyl8 & -7.948 & 0.581 & 3.548 & 0.777 \\
\hline age & -0.419 & 0.049 & 0.285 & 0.065 \\
\hline $\operatorname{age}^{2}$ & 0.006 & 0.002 & 0.003 & 0.002 \\
\hline car & 4.262 & 0.410 & -0.589 & 0.548 \\
\hline cyl $6 \times$ car & -1.439 & 0.560 & -0.661 & 0.749 \\
\hline cyl $8 \times$ car & -1.149 & 0.655 & -2.819 & 0.875 \\
\hline $\mathrm{R}^{2}$ & \multicolumn{2}{|c|}{0.7598} & \multicolumn{2}{|c|}{0.4095} \\
\hline F-value & \multicolumn{2}{|c|}{299.997} & \multicolumn{2}{|c|}{65.775} \\
\hline \# of obs. & \multicolumn{2}{|c|}{672} & \multicolumn{2}{|c|}{672} \\
\hline
\end{tabular}

Table 6. Mean Values of Key Variables Involved in Estimation

\begin{tabular}{ccccccc}
\hline & \multicolumn{6}{c}{ Bundle } \\
\cline { 2 - 6 } Variable & $1(\mathrm{Car})$ & $2(\mathrm{SUV})$ & $3(\mathrm{C}, \mathrm{C})$ & $4(\mathrm{C}, \mathrm{S})$ & $5(\mathrm{~S}, \mathrm{~S})$ & 6 (none) \\
\hline \% of households & 38.43 & 8.22 & 13.08 & 14.46 & 2.80 & 23.01 \\
$\operatorname{VMT}_{1}$ & 11799. & 12977. & 15283. & 10513. & 16151. & -- \\
$V M T_{2}$ & -- & -- & 5554. & 10771. & 5358. & -- \\
price of gas 1 $\left(p_{1}\right)$ & 0.058 & 0.074 & 0.056 & 0.057 & 0.072 & -- \\
price of gas 2 $\left(p_{2}\right)$ & -- & -- & 0.057 & 0.075 & 0.075 & -- \\
vintage1 & 8.62 & 8.24 & 7.63 & 7.89 & 6.87 & -- \\
vintage2 & -- & -- & 9.02 & 8.50 & 8.78 & - \\
Wear & 0.76 & 0.73 & 0.72 & 0.73 & 0.68 & - \\
Wear $_{2}$ & -- & -- & 0.77 & 0.73 & 0.75 & - \\
price of Wear $_{1}\left(q_{1}\right)$ & 15572. & 18010. & 15363. & 15686. & 18052. & - \\
price of Wear $_{2}\left(q_{2}\right)$ & -- & -- & 15301. & 18133. & 18105. & -- \\
expenditure $(y)$ & 22754. & 24574. & 35472. & 33812. & 34246. & 17795. \\
capital cost $(k)$ & 17224. & 20187. & 34157. & 37684. & 40551. & -- \\
capital cost 1 & 17224. & 20187. & 17125. & 17337. & 20232. & -- \\
capital cost 2 & -- & -- & 17032. & 20348. & 20319. & -- \\
\hline
\end{tabular}


Table 7. Estimation Results

\begin{tabular}{|c|c|c|c|}
\hline \multirow[b]{2}{*}{ Parameters } & \multicolumn{2}{|c|}{ Sequential Estimation } & \multirow{2}{*}{$\begin{array}{l}\text { Simultaneous } \\
\text { Estimation }\end{array}$} \\
\hline & Nested Logit & $\begin{array}{l}\text { Continuous } \\
\text { Demands }\end{array}$ & \\
\hline \multirow[t]{2}{*}{$p_{11}, p_{31}\left(\alpha_{C 1}\right)$} & $-0.246 * *$ & $-0.460 * *$ & $-0.433 * *$ \\
\hline & $(0.025)$ & $(0.070)$ & $(0.073)$ \\
\hline \multirow[t]{2}{*}{$p_{32}\left(\alpha_{C 2}\right)$} & -0.045 & $-0.238 *$ & $-0.045 * *$ \\
\hline & $(0.033)$ & $(0.143)$ & $(0.008)$ \\
\hline \multirow[t]{2}{*}{$p_{21}, p_{51}\left(\alpha_{S 1}\right)$} & $-0.237 * *$ & $-0.927 * *$ & $-0.526 * *$ \\
\hline & $(0.028)$ & $(0.054)$ & $(0.105)$ \\
\hline \multirow[t]{2}{*}{$p_{52}\left(\alpha_{S 2}\right)$} & -0.011 & -0.453 & -0.013 \\
\hline & $(0.049)$ & $(0.380)$ & $(0.080)$ \\
\hline \multirow[t]{2}{*}{$p_{4 I}\left(\alpha_{C A R}^{4}\right)$} & $-0.240 * *$ & $-0.374 * *$ & $-0.399 * *$ \\
\hline & $(0.024)$ & $(0.143)$ & $(0.062)$ \\
\hline \multirow[t]{2}{*}{$p_{42}\left(\alpha_{S U V}^{4}\right)$} & $-0.084 * *$ & -1.331 & $-0.662 * *$ \\
\hline & $(0.022)$ & $(1.582)$ & $(0.103)$ \\
\hline \multirow[t]{2}{*}{$q_{1}\left(\alpha_{q 1}\right)$} & $-0.012 * *$ & $-0.370 \mathrm{E}-03$ & $-0.004 * *$ \\
\hline & $(0.003)$ & $(0.002)$ & $(0.001)$ \\
\hline \multirow[t]{2}{*}{$q_{2}\left(\alpha_{q 2}\right)$} & $0.010^{* *}$ & $-0.010 * *$ & $-0.219 \mathrm{E}-36$ \\
\hline & $(0.001)$ & $(0.002)$ & $(0.936 \mathrm{E}-36)$ \\
\hline \multirow[t]{2}{*}{$y(\beta)$} & $-1.408 * *$ & $1.134 * *$ & $-0.420 * *$ \\
\hline & $(0.086)$ & (0.134E-03) & $(0.001)$ \\
\hline \multirow[t]{2}{*}{$k\left(\beta_{1}\right)$} & $-0.671 * *$ & $-0.456 * *$ & $-0.405 * *$ \\
\hline & $(0.108)$ & $(0.034)$ & $(0.023)$ \\
\hline \multicolumn{4}{|l|}{ Choice specific: } \\
\hline constant $2\left(\alpha_{0}^{2}\right)$ & $\begin{array}{c}-1.403 * * \\
(0.278)\end{array}$ & & $\begin{array}{c}0.645^{* *} \\
(0.035)\end{array}$ \\
\hline constant $3\left(\alpha_{0}^{3}\right)$ & $\begin{array}{l}4.219 * * \\
(0.516)\end{array}$ & & $\begin{array}{l}1.860 * * \\
(0.031)\end{array}$ \\
\hline \multirow{2}{*}{ constant $4\left(\alpha_{0}^{4}\right)$} & $5.057 * *$ & & $2.063 * *$ \\
\hline & $(0.650)$ & & $(0.051)$ \\
\hline \multirow{2}{*}{ constant $5\left(\alpha_{0}^{5}\right)$} & $2.401 * *$ & & $2.320 * *$ \\
\hline & $(0.685)$ & & $(0.062)$ \\
\hline \multirow{2}{*}{ constant $6\left(\alpha_{0}^{6}\right)$} & $-2.045 * *$ & & $-0.948 * *$ \\
\hline & $(0.383)$ & & $(0.132)$ \\
\hline \multicolumn{4}{|l|}{ Demand-Specific: } \\
\hline \multirow[t]{2}{*}{ constant $1\left(\alpha_{V 1}\right)$} & & $9.578 * *$ & $0.302 * *$ \\
\hline & & $(0.179)$ & $(0.087)$ \\
\hline \multirow[t]{2}{*}{ constant $2\left(\alpha_{V 2}\right)$} & & $7.361 * *$ & $0.805 * *$ \\
\hline & & $(0.187)$ & $(0.088)$ \\
\hline \multirow[t]{2}{*}{ constant $3\left(\alpha_{W 1}\right)$} & & $9.346^{*}$ & $2.580 * *$ \\
\hline & & $(5.007)$ & $(0.298)$ \\
\hline \multirow{2}{*}{ constant $4\left(\alpha_{W 2}\right)$} & & $5.147 * *$ & $5.114 * *$ \\
\hline & & $(0.176)$ & $(1.259)$ \\
\hline
\end{tabular}

(continued on the next page) 
Table 7. Estimation Results (cont'd)

\begin{tabular}{|c|c|c|c|}
\hline Famsize & $\begin{array}{c}0.332 \\
(0.542)\end{array}$ & $\begin{array}{c}0.072 * * \\
(0.002)\end{array}$ & $\begin{array}{c}0.058 * * \\
(0.001)\end{array}$ \\
\hline \multirow[t]{2}{*}{ Earnr } & $0.270 * *$ & $0.067 * *$ & $0.032 * *$ \\
\hline & $(0.067)$ & $(0.001)$ & $(0.183 \mathrm{E}-03)$ \\
\hline \multirow[t]{2}{*}{ Kids } & 0.510 & $0.081 * *$ & $-0.031 * *$ \\
\hline & $(0.527)$ & $(0.002)$ & $(0.001)$ \\
\hline \multirow[t]{2}{*}{ Drivers } & 0.190 & $0.060 * *$ & $-0.041 * *$ \\
\hline & $(0.535)$ & $(0.001)$ & $(0.001)$ \\
\hline \multirow[t]{2}{*}{ Metro } & $-0.552 * *$ & $-0.012 * *$ & $0.012 * *$ \\
\hline & $(0.123)$ & $(0.002)$ & $(0.474 \mathrm{E}-03)$ \\
\hline \multirow[t]{2}{*}{ Pop4 } & $-0.340 * *$ & $-0.013 * *$ & $0.012 * *$ \\
\hline & $(0.085)$ & $(0.001)$ & $(0.290 \mathrm{E}-03)$ \\
\hline \multirow[t]{2}{*}{ Urban } & $-0.441 * *$ & $-0.058 * *$ & $0.105 * *$ \\
\hline & $(0.161)$ & $(0.002)$ & $(0.001)$ \\
\hline \multirow[t]{2}{*}{ Age } & $0.046 * *$ & $-0.007 * *$ & $0.004 * *$ \\
\hline & $(0.003)$ & (0.290E-04) & $(0.128 \mathrm{E}-04)$ \\
\hline \multirow[t]{2}{*}{ White } & 0.056 & $0.136 * *$ & $0.097 * *$ \\
\hline & $(0.091)$ & $(0.001)$ & $(0.386 \mathrm{E}-03)$ \\
\hline \multirow[t]{2}{*}{ Male } & 0.057 & $0.109 * *$ & $0.004 * *$ \\
\hline & $(0.085)$ & $(0.001)$ & $(0.240 \mathrm{E}-03)$ \\
\hline \multirow[t]{2}{*}{ Educ } & 0.020 & $0.058 * *$ & $0.036 * *$ \\
\hline & $(0.072)$ & $(0.001)$ & $(0.263 \mathrm{E}-03)$ \\
\hline \multirow[t]{2}{*}{ Northwest } & 0.244 & $0.042 * *$ & $0.046 * *$ \\
\hline & $(0.179)$ & $(0.001)$ & $(0.386 \mathrm{E}-03)$ \\
\hline \multirow[t]{2}{*}{ Midwest } & $0.401 * *$ & $0.064 * *$ & $0.059 * *$ \\
\hline & $(0.173)$ & $(0.001)$ & $(0.380 \mathrm{E}-03)$ \\
\hline \multirow[t]{2}{*}{ South } & $-0.726^{* *}$ & $-0.150 * *$ & $0.072 * *$ \\
\hline & $(0.121)$ & $(0.001)$ & $(0.374 \mathrm{E}-03)$ \\
\hline \multirow[t]{2}{*}{$\lambda_{1}$} & $0.814 * *$ & & $0.138 * *$ \\
\hline & $(0.053)$ & & $(0.006)$ \\
\hline \multirow[t]{2}{*}{$\lambda_{2}$} & $0.066 * *$ & & $0.103 * *$ \\
\hline & $(0.003)$ & & $(0.005)$ \\
\hline Log Likelihood & -28917.8 & -786857 & $-0.310 \mathrm{E}+07$ \\
\hline
\end{tabular}

$*$ indicates 0.10 significance level, and ** indicates 0.05 significance level. 
Table 8. Elasticities of Discrete Choices for each Variable

\begin{tabular}{|c|c|c|c|c|c|c|}
\hline \multirow[b]{2}{*}{ Variable } & \multicolumn{6}{|c|}{ Bundle } \\
\hline & 1 (Car) & 2 (SUV) & $3(\mathrm{C}, \mathrm{C})$ & $4(\mathrm{C}, \mathrm{S})$ & $5(\mathrm{~S}, \mathrm{~S})$ & 6 (none) \\
\hline \multicolumn{7}{|c|}{ Sequential: ${ }^{a}$} \\
\hline$p$ & 0.015 & -0.106 & 0.006 & $-0.177 \mathrm{E}-03$ & 0.034 & -- \\
\hline$q$ & -0.207 & 3.618 & -0.116 & -0.033 & -6.077 & -- \\
\hline$q_{c a r}$ & 1.530 & -6.318 & 0.139 & 0.127 & -3.470 & -- \\
\hline$q_{s u v}$ & -1.737 & 9.937 & -0.255 & -0.160 & -2.603 & -- \\
\hline$y$ & -0.106 & 0.591 & -0.042 & -0.006 & -0.011 & -0.006 \\
\hline$k$ & 0.086 & -0.427 & 0.061 & 0.008 & -0.303 & -- \\
\hline$k_{c a r}$ & -0.008 & 0.127 & 0.056 & -0.944 & 4.336 & -- \\
\hline$k_{\text {suv }}$ & 0.110 & -0.413 & 0.134 & -1.099 & 4.703 & -- \\
\hline \multicolumn{7}{|c|}{ Simultaneous: ${ }^{\mathrm{b}}$} \\
\hline$p$ & 0.009 & -0.073 & 0.695 & -0.793 & 0.020 & -- \\
\hline$q$ & 0.025 & 0.193 & 0.066 & 0.283 & -0.001 & -- \\
\hline$q_{c a r}$ & 0.177 & -0.966 & 0.151 & 0.352 & -0.147 & -- \\
\hline$q_{s u v}$ & -0.153 & 1.159 & -0.085 & -0.069 & 0.146 & -- \\
\hline$y$ & 0.341 & -1.203 & -0.818 & 0.634 & 0.010 & -0.074 \\
\hline$k$ & -0.321 & 0.390 & 1.655 & -6.319 & -0.377 & -- \\
\hline$k_{c a r}$ & -1.229 & 7.315 & -13.021 & 7.345 & 1.263 & -- \\
\hline$k_{s u v}$ & 0.908 & -6.925 & 14.676 & -13.665 & -1.640 & -- \\
\hline
\end{tabular}

${ }^{\text {a }}$ Calculation based on estimates in column 1 of Table 7.

${ }^{\mathrm{b}}$ Calculation based on estimates in column 3 of Table 7. 
Table 9. Short-Run Elasticities of Continuous Demands

\begin{tabular}{|c|c|c|c|c|c|c|}
\hline \multirow[b]{2}{*}{ Variable } & \multicolumn{5}{|c|}{ Bundle } & \multirow{2}{*}{$\begin{array}{c}\text { Total } \\
\text { Emissions }^{\mathrm{c}}\end{array}$} \\
\hline & 1 (Car) & 2(SUV) & $3(\mathrm{C}, \mathrm{C})$ & $4(\mathrm{C}, \mathrm{S})$ & $5(\mathrm{~S}, \mathrm{~S})$ & \\
\hline \multicolumn{7}{|c|}{ Sequential: ${ }^{a}$} \\
\hline$p$ & -0.026 & -0.066 & -0.038 & -0.117 & -0.098 & -0.211 \\
\hline$q$ & 0.012 & 0.013 & 0.306 & 0.360 & 0.362 & 0.631 \\
\hline$q_{c a r}$ & 0.012 & -- & 0.306 & 0.012 & -- & 0.368 \\
\hline$q_{s u v}$ & -- & 0.013 & -- & 0.349 & 0.362 & 0.263 \\
\hline$y$ & -2.581 & -2.788 & -4.024 & -3.836 & -3.885 & -11.472 \\
\hline$k$ & -1.570 & -1.840 & -3.113 & -3.434 & -3.695 & -8.746 \\
\hline \multicolumn{7}{|c|}{ Simultaneous: ${ }^{b}$} \\
\hline$p$ & -0.024 & -0.037 & -0.026 & -0.070 & -0.038 & -0.136 \\
\hline$q$ & 0.122 & 0.141 & 0.120 & 0.123 & 0.141 & 0.434 \\
\hline$q_{c a r}$ & 0.122 & -- & 0.120 & 0.123 & -- & 0.293 \\
\hline$q_{s u v}$ & -- & 0.141 & -- & 7.933E-36 & 0.141 & 0.141 \\
\hline$y$ & 0.956 & 1.032 & 1.490 & 1.420 & 1.438 & 4.246 \\
\hline$k$ & -1.397 & -1.637 & -2.770 & -3.056 & -3.288 & -7.783 \\
\hline
\end{tabular}

Each entry is the elasticity of $V M T$ or Wear, in the first or second vehicle, with respect to each variable.

${ }^{\text {a }}$ Calculation based on estimates in column 2 of Table 7.

${ }^{\mathrm{b}}$ Calculation based on estimates in column 3 of Table 7.

c The last column is the percent change in total emissions, $E=\sum E P M \times$ miles, adding over all vehicles in all bundles, for a one percent change in each variable. 